\title{
UROGRAFIA POR TOMOGRAFIA COMPUTADA MULTICORTE (UROTAC): ESTUDIO DESCRIPTIVO UTILIZANDO LA TECNICA DE "SPLIT BOLUS"
}

\author{
Drs. Karina Hermosilla $M^{(1)}$, Roberto Cabrera $T^{(1)}$, Benjamín Horwitz $Z^{(1)}$, Rodrigo Raurich $\mathbf{S}^{(1)}$, Marco Barbieri H(2) \\ Samuel Gac $H^{(2)}$, Pablo Soffia $S^{(2)}$, Claudia Páez $A^{(3)}$, Oscar Morgado $H^{(3)}$. \\ 1. Médicos. Residentes de Radiología, Facultad de Medicina Clínica Alemana-Universidad del Desarrollo. Santiago-Chile. \\ 2. Médicos Radiólogos. Docentes de Radiología, Hospital Padre Hurtado. Santiago-Chile. Facultad de Medicina \\ Clínica Alemana-Universidad del Desarrollo. Santiago, Chile. \\ 3. Tecnólogos Médicos. Servicio de Radiología, Hospital Padre Hurtado. Santiago-Chile.
}

\section{MULTISLICE CT UROGRAPHY (URO-CT): A DESCRIPTIVE STUDY USING SPLIT BOLUS TECHNIQUE}

\begin{abstract}
Multislice computed tomography provides high spatial and temporal resolution images in addition to high quality multiplanar and three-dimensional reconstructions. As a result of this diagnostic efficacy, the Computed Tomography Urography (Uro-CT) has become the technique of choice for evaluating the urinary tract, virtually replacing the traditional urography examination. At Padre Hurtado Hospital, Santiago, Chile, we conducted a retrospective analysis to review our experience with Uro-CT scanning and split bolus technique, which has the potential to yield a synchronous nephrographic and excretory phase of the urinary system, thus reducing radiation dose for patients, number of images and costs generated by MDCT urography. A series of 31 cases is presented, along with description of techniques applied as well as study main findings.
\end{abstract}

Keywords: Genitourinary system, Radiation dosage, Split bolus, Urography computed tomography.

Resumen: La tomografía computada multicorte permite obtener imágenes de alta resolución espacial y temporal además de reconstrucciones multiplanares y tridimensionales de gran calidad, lo que ha hecho que la Urografía por Tomografía Computada (UroTAC) se convierta en la técnica de elección para la evaluación del tracto urinario, reemplazando prácticamente a la urografía tradicional. En el Hospital Padre Hurtado, revisamos nuestra experiencia con UroTAC y técnica de "split bolus" que permite obtener simultáneamente una fase nefrográfica y excretora del sistema urinario mediante una sola adquisición, lo que disminuye la dosis de radiación al paciente, el número de imágenes y los costos de la UroTAC estándar. Presentamos una serie de 31 pacientes estudiados, describiendo la técnica y los

Hermosilla K y cols. Urografía por tomografía computada multicorte (UroTac): Estudio descriptivo utilizando la técnica de "split bolus". Rev Chil Radiol 2009; 15(2): 65-69.

Correspondencia: Dra. Karina Hermosilla $M$.

khermosilla@gmail.com

Trabajo recibido el 26 de febrero de 2008, aceptado para publicación el 14 de abril 2009. principales hallazgos obtenidos en ellos.

Palabras clave: Aparato Genitourinario, Dosis de Radiación, UroTAC, Split bolus.

\section{Introducción}

Actualmente, los tomógrafos computados multicortes (TCMC) permiten obtener imágenes de alta resolución espacial y temporal, lo que sumado a las reconstrucciones multiplanares y tridimensionales de gran calidad han hecho que la Urografía por Tomografía Computada (UroTAC) se convierta en la técnica de elección para la evaluación del tracto urinario(1), reemplazando prácticamente a la urografía tradicional(2), especialmente en pacientes con hematuria y factores de riesgo para desarrollar cáncer de urotelio ${ }^{(3)}$.

La UroTAC permite la evaluación completa del tracto urinario (sistema colector, uréteres y vejiga) y su principal objetivo es la detección y caracterización de neoplasias malignas del urotelio ${ }^{(4)}$. Además es útil en la visualización de litiasis urinaria, tumores renales, evaluación de lesiones traumáticas o infecciosas y malformaciones congénitas ${ }^{(3)}$, permitiendo evaluar además el resto del abdomen y pelvis, lo que es útil en la etapificación de pacientes con neoplasias del tracto urinario y también en el diagnóstico de patología extraurinaria(2).

Tradicionalmente, la UroTAC consiste en:

- Adquisición de imágenes antes de la administración de contraste intravenoso, para la detección de urolitiasis.

- Después de la administración de contraste intravenoso se realiza una segunda adquisición en fase corticomedular, una tercera en fase nefrográfica y una cuarta adquisición en fase de excreción del medio de contraste ${ }^{(3,4)}$.

- Si no se ha logrado una opacificación adecuada de las estructuras que se desea evaluar, se realiza finalmente una adquisición adicional en fase más tardía.

Se han desarrollado diferentes protocolos con el objetivo de optimizar esta técnica y disminuir la dosis de radiación efectiva que reciben los pacientes ${ }^{(4,5)}$. Dentro de éstas, la aplicación de un bolo de contraste intravenoso fraccionado (split bolus) en distintos tiempos y realización posterior de una sola adquisición de imágenes, sincronizando las fases nefrográfica y urográfica, ha demostrado ser una alternativa viable ${ }^{(5,6)}$. 
El principal objetivo de esta revisión descriptiva y retrospectiva, es identificar los principales hallazgos en nuestra serie de pacientes, estudiados por distintas patologías: neoplasias del tracto urinario, malformaciones congénitas y otras patologías adquiridas. También describiremos en detalle el protocolo usado en nuestro servicio y mostraremos los resultados obtenidos con la aplicación de esta técnica.

\section{Material y métodos}

Se realizó una evaluación retrospectiva de las imágenes de UroTAC con técnica de split bolus realizados en el Servicio de Imaginología del Hospital Padre Hurtado, entre julio de 2007 y julio de 2008, a 31 pacientes referidos para evaluación de hematuria y otras patologías del tracto urinario. Se excluyeron los pacientes con creatinina sérica mayor a $1,5 \mathrm{mg} / \mathrm{dl}$.

Todos los exámenes fueron realizados en un tomógrafo computado multicorte de 16 canales (Toshiba Aquilion), usando parámetros técnicos estandarizados (Tabla I).

Tabla I. Parámetros técnicos utilizados.

\begin{tabular}{ll}
$\mathrm{mA}$ & $400 \mathrm{~mA}$ \\
$\mathrm{kV}$ & $120 \mathrm{kV}$ \\
Pitch & 1.5 \\
Colimación & $1 \times 16 \mathrm{~mm}$ \\
Tiempo de rotación & $0,5 \mathrm{seg}$ \\
Filtro de reconstrucción & 2 (partes blandas) \\
Tiempo promedio & $18,21 \mathrm{seg}$. \\
Dosis de radiación estimada & $560 \mathrm{mGy} \mathrm{cm}$ \\
Reconstrucción & $1 \mathrm{c} / 0,8 \mathrm{~mm}$ \\
\hline
\end{tabular}

Los cortes finos de cada estudio fueron almacena-

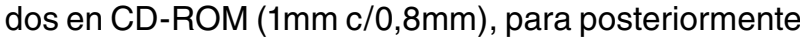
ser reevaluados en una estación de trabajo Vitrea ${ }^{2} 2$ (Vital Images Inc, Minnetonka, USA), por dos radiólogos con experiencia en la interpretación de imágenes de TCMC de abdomen y pelvis. Se realizaron reformateos multiplanares, MIP y VR, dependiendo de los hallazgos encontrados.

El protocolo utilizado fue el siguiente:

1. Parámetros técnicos

- Descritos en Tabla I.

2. Detalles de la realización del examen

- El paciente deberá beber 500 a $700 \mathrm{ml}$ de agua,mientras se encuentra en la sala de espera.

- Una vez en la mesa del tomógrafo, con el paciente en decúbito supino, se realiza un scouty una adquisición sin contraste desde el nivel vertebral T12 hasta $2 \mathrm{~cm}$ por debajo de la sínfisis púbica.

- Luego, con el cronómetro digital en $0(t=0)$ se inyectan $100 \mathrm{ml}$ de contraste no iónico loversol $320 \mathrm{mg} / \mathrm{ml}$ (Optiray®, Tyco Healthcare, Hazelwood, USA) por vía intravenosa (2-3 ml/seg).

- El paciente se levanta y camina dentro de la sala del tomógrafo.
- A los 6 minutos ( $t=6 \mathrm{~min}$ ), el paciente se acuesta en la mesa, en decúbito supino, y se realiza un nuevo scout.

- A los 9 minutos ( $t=9 \mathrm{~min}$ ) se le inyectan $50 \mathrm{ml}$ más del mismo contraste intravenoso y se realiza una nueva adquisición, ahora desde el diafragma hasta la sínfisis púbica. De esta manera, en una sola adquisición se obtiene las fases nefrográfica y pielográfica del sistema urinario (Figura 1).
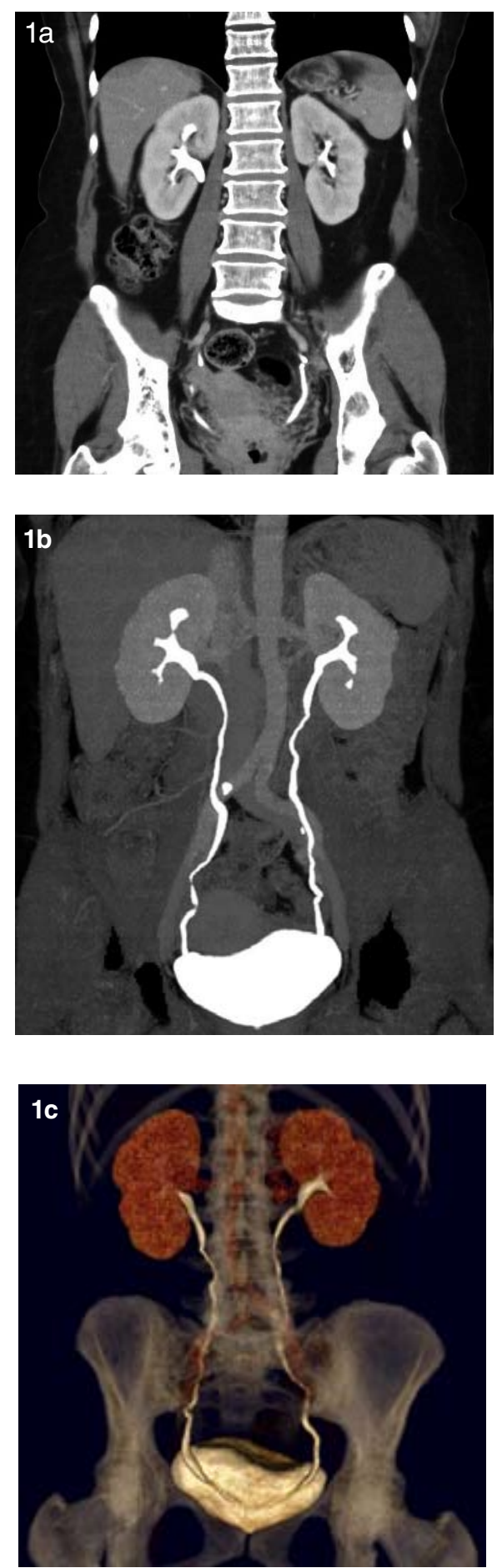

Figura 1a, b y c. a) MPR coronal, riñones normales en fase nefrográfica y contraste simultáneo del sistema excretor. b) MIP coronal, que muestra opacificación completa del sistema de eliminación y de la vejiga. c)Volume Rendering (VR) en visión posteroanterior, demostrando la anatomía renal, del sistema excretor y de la vejiga. 
- Si los uréteres no están completamente opacificados o no se obtiene una adecuada delimitación de la pared vesical, el paciente debe ser colocado en decúbito prono para realizar una tercera y última adquisición, sin ningún tiempo de espera adicional.

\section{Resultados}

Se realizaron 33 UroTAC con técnica de split bolus en 31 pacientes, 16 de ellos de sexo masculino y 15 de sexo femenino, con un promedio de edad de 54,4 años (rango de 17 a 87 años).

El $48 \%$ de los pacientes fueron referidos con el diagnóstico de hematuria, 12\% para evaluación de malformaciones congénitas y $9 \%$ por hidronefrosis de causa no explicada. Otros diagnósticos de referencia incluían infecciones urinarias recurrentes, tuberculosis del tracto urinario y cistitis actínica.

Un $84 \%$ de los exámenes fueron positivos para patología del sistema urinario, que en su mayoría correspondían a alteraciones benignas (63\%) tales como quistes renales, lesiones infecciosas, malformaciones congénitas o variantes anatómicas (Figuras 2-6) y urolitiasis.
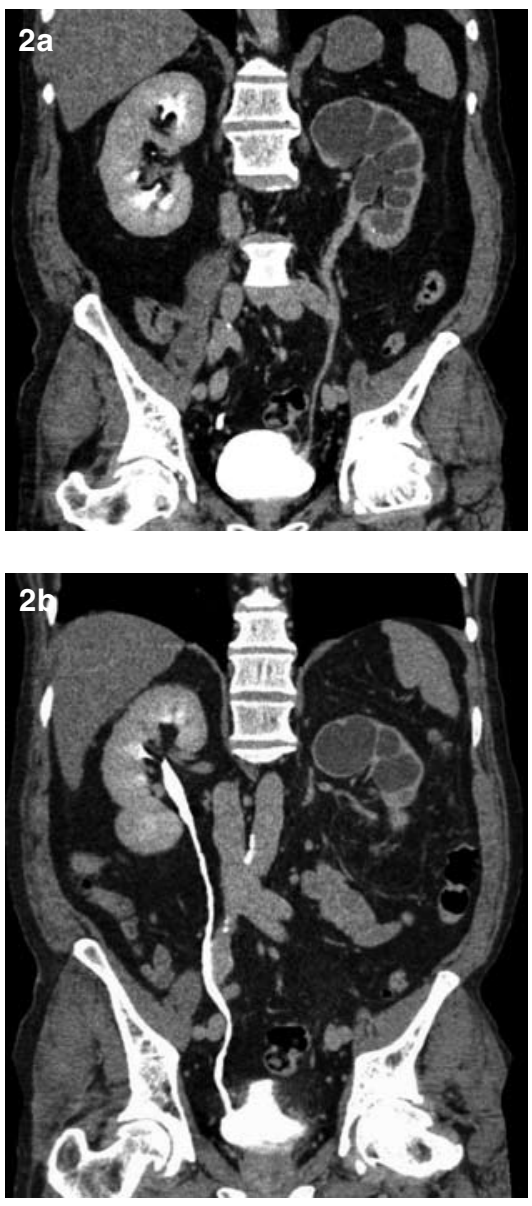
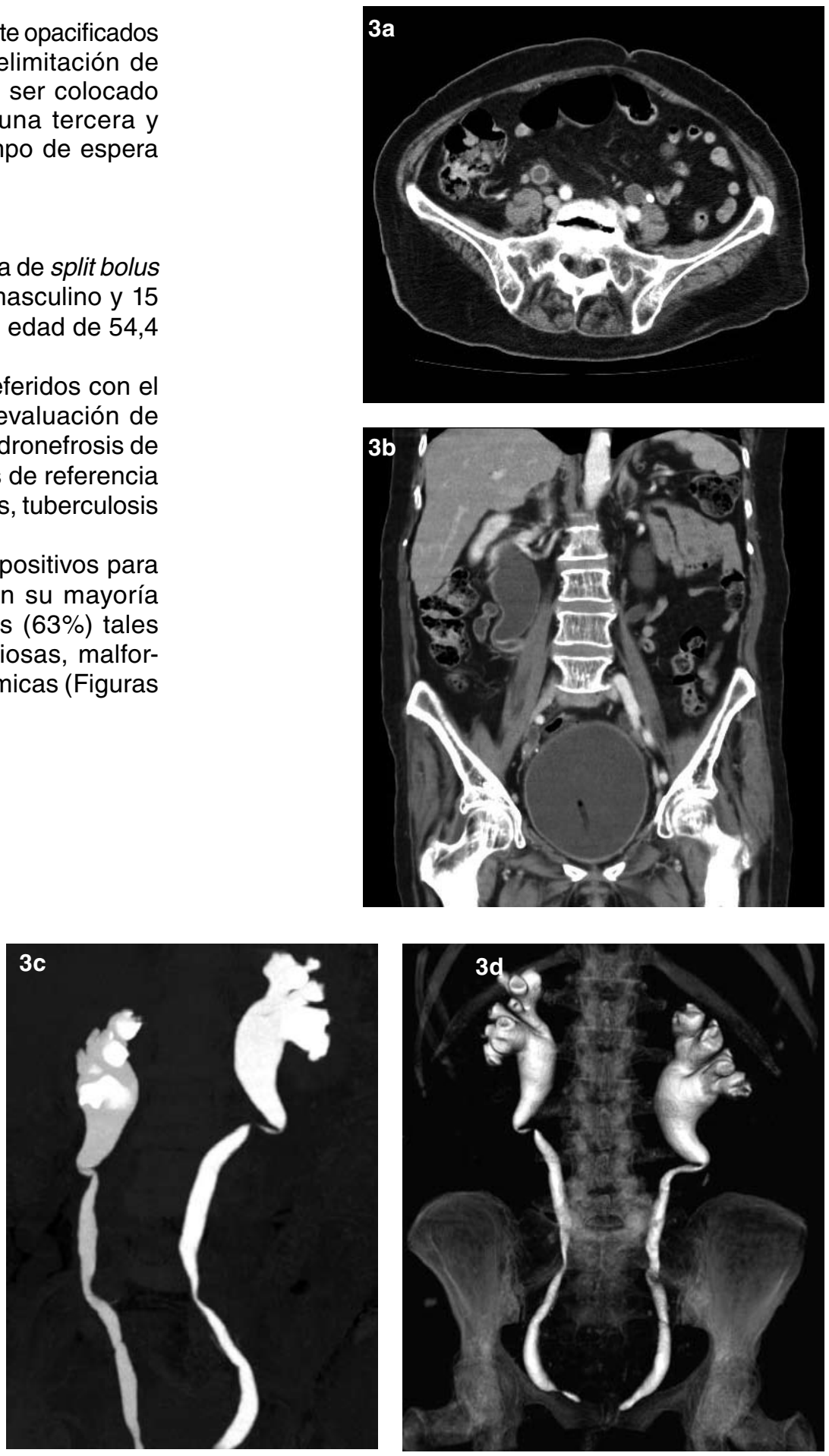

Figura 3 a-d. a) Imagen axial donde se aprecia engrosamiento anular del uréter medio derecho. b) MPR coronal del mismo paciente donde se observa engrosamiento de aspecto inflamatorio del uréter proximal. $c$ y d) MIP $3 D$ y $V R$ del mismo paciente que muestra estenosis infundibuliforme del uréter distal izquierdo.

Figura 2 a y b. a) MPR coronal, que demuestra hidronefrosis izquierda asociada a severo adelgazamiento cortical. Existe un engrosamiento parietal difuso del uréter con ausencia de lumen y cambios inflamatorios de la grasa periureteral. Se confirmó TBC mediante baciloscopías de orina. b)MPR coronal, del mismo paciente que muestra indemnidad del sistema excretor derecho. 
Figura 4 a $\boldsymbol{y}$ b. a) MPR oblicuo-coronal que muestra riñones en herradura, con un puente de parénquima completo uniendo los polos inferiores. b) Imagen axial en fase nefro-urográfica, del mismo paciente en el que se observa un área de menor atenuación corticomedular en el riñón derecho, compatible con pielonefritis focal.
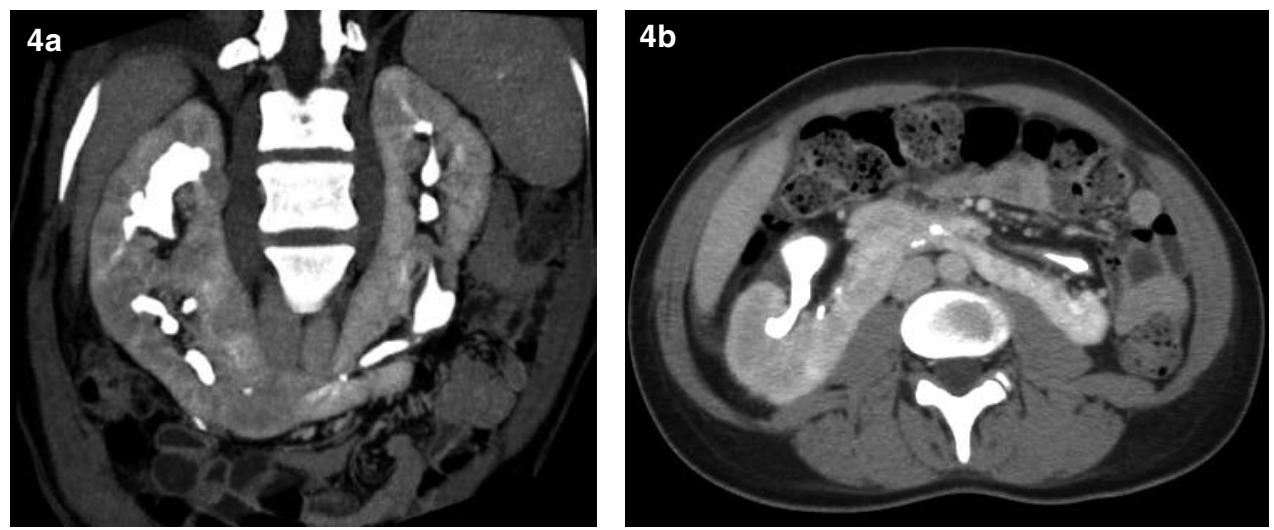
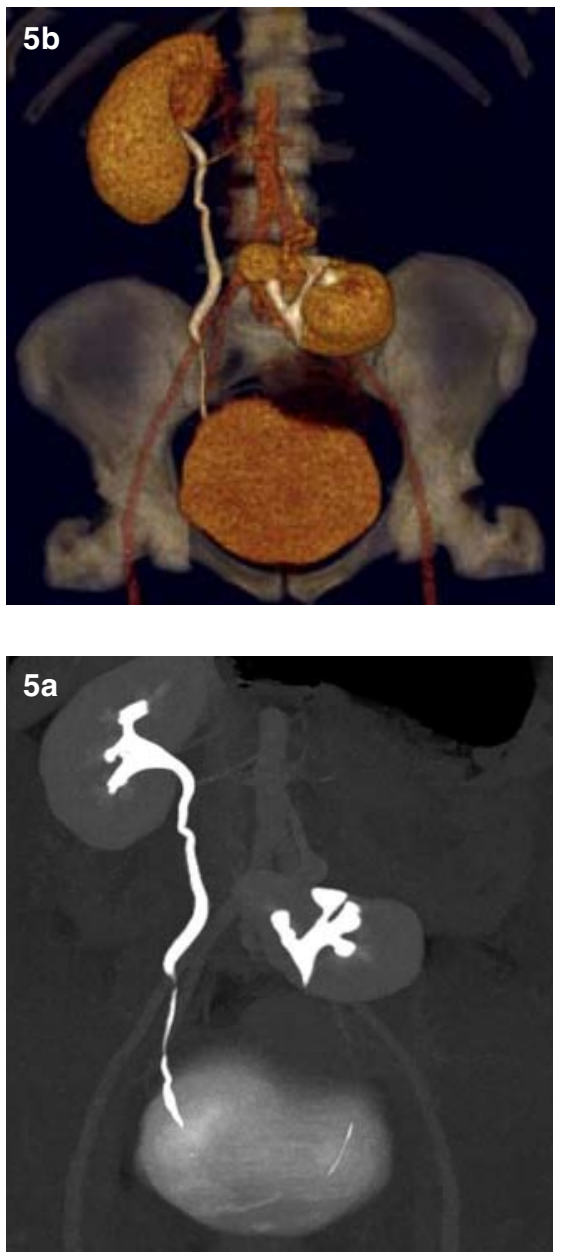
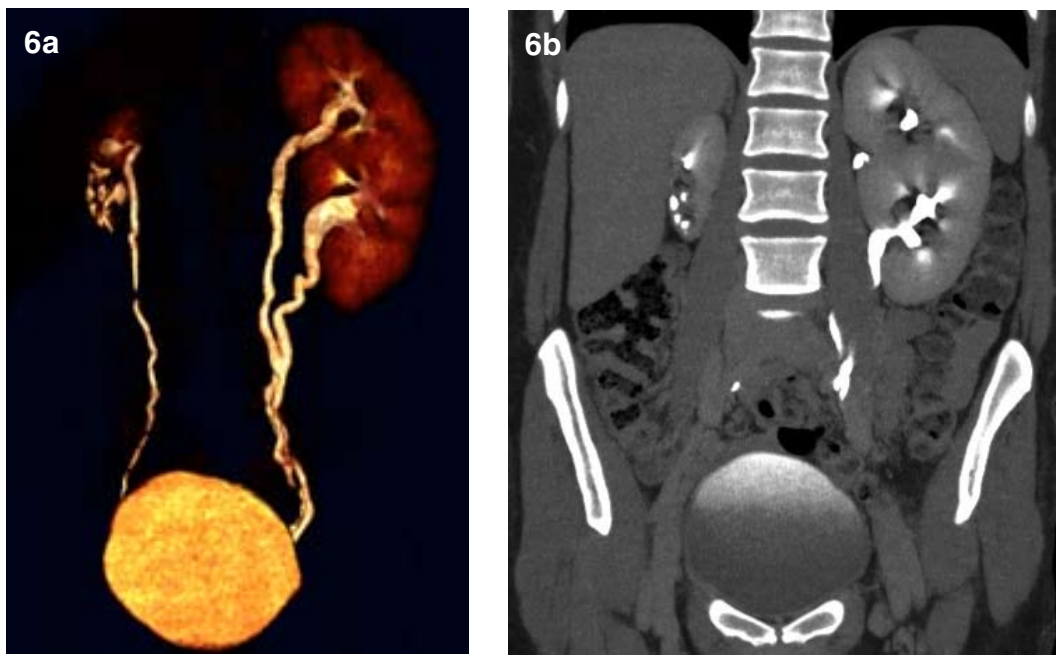

Figura 6 a y b. a) VR que muestra doble sistema excretor bilateral, con atrofia del sistema inferior derecho. b) MPR oblicuo coronal, del mismo paciente, que muestra la atrofia renal derecha con marcado adelgazamiento cortical del sistema inferior.

Figura 5 a y b. MIP $3 D$ y VR que demuestran ectopia renal, con riñón izquierdo pelviano.

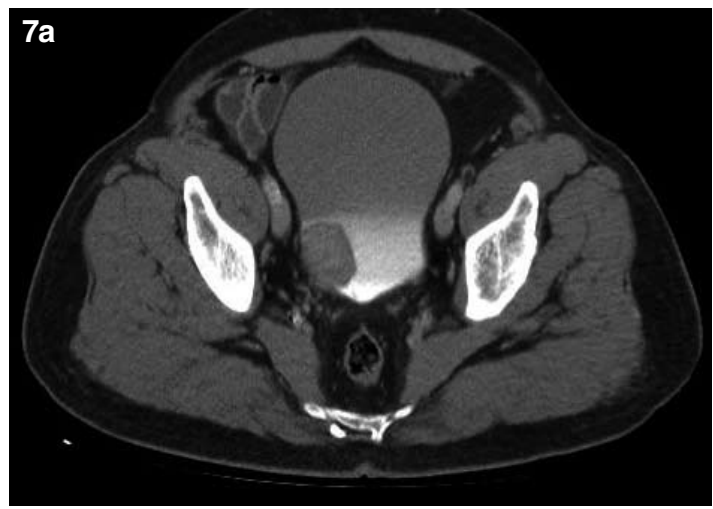

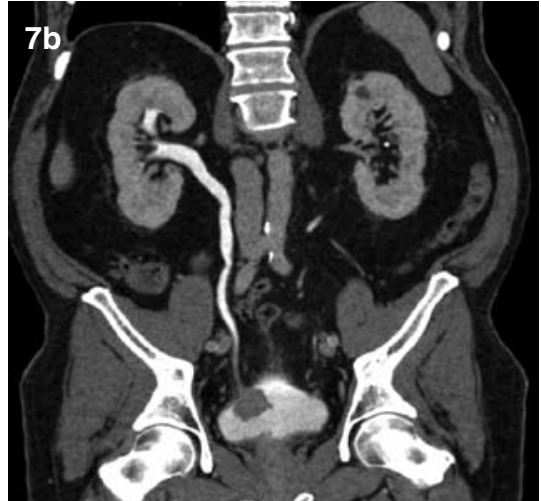

Figura 7 a y b. Imagen axial y MPR coronal, donde se observa un tumor intravesical, polipoídeo, que compromete la unión ureterovesical y el uréter distal derecho. 

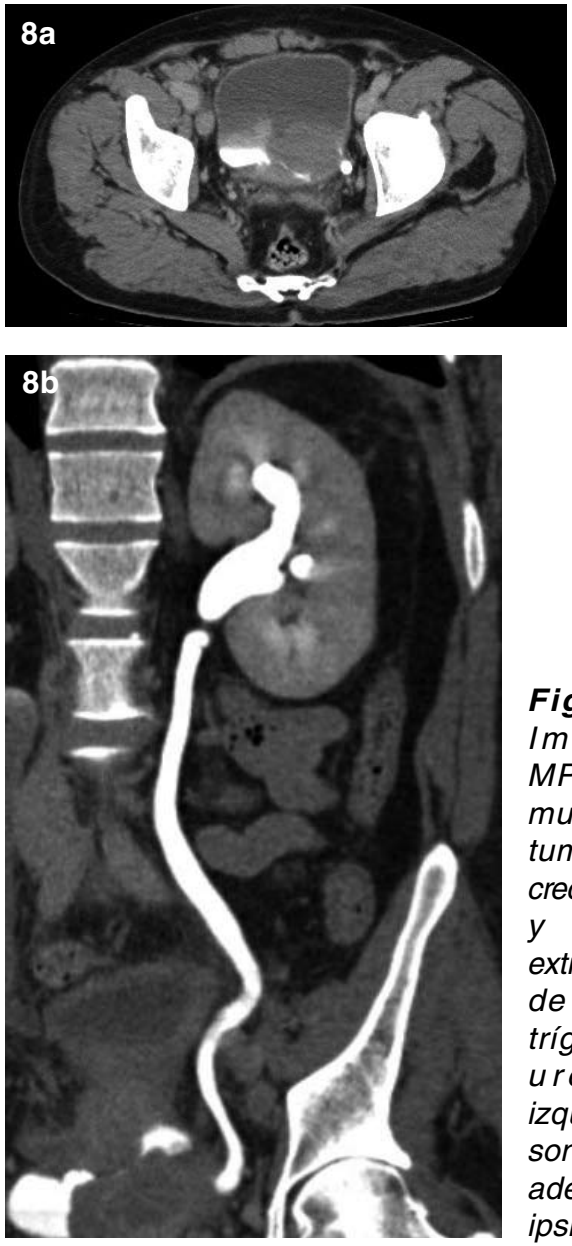

Figura 8 a $y$ b. Imagen axial y MPR coronal que muestran un gran tumor vesical, con crecimiento endofítico y compromiso extraseroso, además de infiltración del trígono y la unión ureterovesical izquierda. También son visibles algunas adenopatías ilíacas ipsilaterales.

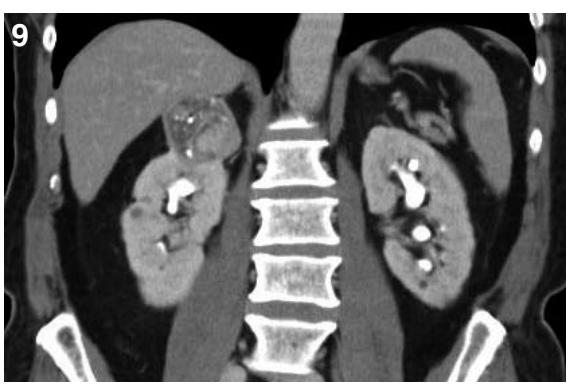

Figura 9. MPR coronal, que muestra un tumor sólido, exofítico, en el polo superior del riñón derecho, con pequeñas calcificaciones en su espesor, compatible con un carcinoma de células renales.

Se evidenció patología maligna en un $12 \%$ de los estudios realizados: 3 neoplasias de urotelio (Figura 7, 8) y un hipernefroma (Figura 9), todos ellos comprobados mediante estudio anátomo-patológico.

Un $15 \%$ de los estudios resultaron normales. Se detectó patología extraurinaria en el $27 \%$ de los exámenes realizados, incluyendo: colelitiasis, hernias inguinales que contenían parte de la vejiga, trombosis de la vena cava y enfermedad diverticular.

\section{Discusión}

La UroTAC con técnica split bolus constituye un método de alto rendimiento para evaluar patología del tracto urinario, que permite realizar una caracterización del urotelio desde el sistema colector renal hasta la vejiga, en un corto período de tiempo(4).

Esta técnica reduce la radiación efectiva recibida por el paciente, al eliminar una o más fases de la UroTAC convencional. Esto es relevante, considerando que la mayor parte de nuestros pacientes presentaban patología benigna del sistema urinario, lo que es concordante con los resultados publicados en la literatura ${ }^{(5)}$. Además produce un menor número de imágenes, facilitando su interpretación ${ }^{(6)}$.

El protocolo usado en este estudio incorpora el uso de un scout digital a los 6 minutos, para aumentar la probabilidad de visualizar los uréteres opacificados, con un mínimo aumento de la radiación, que asegura un examen de óptima calidad(7).

Una de las limitaciones de esta técnica se produce en la evaluación de neoplasias que producen un mínimo engrosamiento de la pared vesical, donde se ha reportado una sensibilidad de $74 \%{ }^{(5)}$. Sin embargo, se debe considerar que en pacientes con hematuria y factores de riesgo para neoplasia de urotelio se debe realizar una cistoscopía convencional, que sigue siendo el gold standard para la evaluación de la mucosa vesical (4). En nuestra serie hubo tres casos de neoplasia vesical, todos ellos con compromiso transmural, por lo que la presencia de contraste en el lumen no fue una limitante para su evaluación.

Esta técnica, aunque no considera una fase arterial o corticomedular, sigue teniendo un adecuado rendimiento para detección de carcinoma de células renales ${ }^{(5)}$; las 4 neoplasias detectadas en nuestra serie tuvieron una adecuada correlación anátomo-patológica.

En resumen, en nuestra experiencia ésta técnica -que reduce la exposición a radiación de los pacientesresulta de utilidad en el estudio de patologías del tracto urinario, con resultados semejantes a lo descrito en la literatura.

\section{Bibliografía}

1. Meindl T, Coppenrath E, Degenhart C, Müller-Lisse $U$, Reiser M. MDCT urography: experience with biphasic excretory phase examination protocol. Eur Radiol 2007; 17: 2512-2518.

2. Tsili A, Efremidis S, Kalef-Ezra, Giannakis D, Alamanos $\mathrm{Y}$, Sofikitis $\mathrm{N}$ et al. Multi-Detector row CT urography on a 16-row CT scanner in the evaluation of urothelial tumors. Eur Radiol 2007; 17: 1046-1054.

3. Van Der Molen A, Cowan N, Müller-Lisse U, NolteErnsting C, Takahashi S, Cohan R. CT urography: definition, indications and techniques. A guideline for clinical practice. Eur Radiol 2008; 18: 4-11.

4. Noroozian M, Cohan R, Caoili E, Cowan N, Ellis J. Multislice CT urography: state of the art. The British Journal of Radiology 2004; 77: 74-86.

5. Chow L, Kwan S, Olcott E, Sommer G. Split-bolus MDCT Urography with synchronous nephrographic and excretory phase enhancement. AJR 2007; 189: 314-322.

6. Nolte-Ernsting C, Cowan N. Understanding multislice CT urography techniques: many roads lead to Rome. Eur Radiol 2006; 16: 2670-2686.

7. McCarthy $\mathrm{C}$, Cowan N. Multidetector CT urography for urothelial imaging. Radiology 2002; 225-237. 